\title{
Heat Dissipation Simulation Research of LED Downlight and Optimization of Light Source Layout
}

\author{
Chen Jie, Chen Zhong \\ School of Physics and Mechanical \& Electrical \\ Engineering, Xiamen University \\ Xiamen, 361005, China \\ e-mail: chenjie@xmhl.com.cn
}

\author{
Chen Jie,Li Xiaohong,Shen Yafeng,Xiong \\ Jingkang, Wang Yangxia \\ Xiamen Hualian Electronics Co., Ltd \\ Xiamen, 361008, China \\ e-mail: chenjie@xmhl.com.cn
}

\begin{abstract}
In order to solve the heat dissipation problem of LED (light-emitting diode) downlight, CFD thermal simulation software was used to establish LED downlight dissipation model. Material's thermal conductivity, thermal resistance, thermal emissive values, heat load forms and other factors were all taken in considered, and then numerical simulation combined with laboratory measurement methods was used to analysis the lamp's dissipation. Based on this method, focused on the dissipation effect with different LED quantities and LED ring distances, and then optimized light source layout of current LED downlight products. After experimental verification, LED working temperatures were more ideal after the light source layout optimized, and it can improve the LED lamp lifetime effectively, this result also has important practice significance in the future LED downlight design process.
\end{abstract}

Keywords-lighting;LED downlight;heat dissipation; modeling; simulation

\section{INTRODUCTION}

The light-emitting diode (LED) as lighting faced a critical problem of heat dissipation. LED only has 20\% 30\% photoelectric conversion efficiency, and the rest about $70 \%$ of the total energy is converted into heat, creating a thermal problem. If the chip's heat of the LEDs can't be dissipated effectively, it will make the PN junction temperature too high. Furthermore, this will result in chip luminous efficiency reduced, emission spectrum red shift,colour temperature drop[1],lifetime shorten ,even can led to LED permanent failures[2].Recently ,LED cooling methods can be divided into two categories: passive cooling and active cooling. Such as natural convection, heat pipe technology, plate technology, loop heat pipe technologies are passive cooling solutions [3]; wind cooling, microchannel heat convection, semiconductor refrigeration, phase changed cooling [4] and other methods are belong to active cooling methods [5].These heat dissipating structure just can be used effectively in road lighting such as street lamps or tunnel lamps because they are relatively large and complex. Indoor LED lighting such as LED downligts are mainly using natural heat dissipation method as the limiting of size, appearance, working environment and so on.

LED downlight with LED as its light source, which is improved based on the traditional lamp structure. So, LED downlight has all characteristics of traditional downlight, at the same time it also has all the advantages of LED: energy saving, low carbon, long lifetime, high Color Rending Index (CRI), fast response speed and so on [6]. LED downlight has been designed beautifully and lightly, overall unity of the building will be maintained in the LED downlight installation process because LED downlight will be hidden interior of decoration architectural. Chip on Board (COB), high power LED $(\geq 1 \mathrm{~W})$ array and small-medium power LED $(\leq 0.5 \mathrm{~W})$ array are the top three light source forms used in LED downlight.Especially, the optical effect of smallmedium power LED array light source is the best form, for its soft and uniform visual effect, most of current LED downlights adopt this kind of source for this reason.

A comprehensive heat conduction, heat convection and heat radiation analysis of LED lamp can be simulated by using finite element computational fluid dynamics (CFD) software, the results includes the temperature field, flow field and etc.So, the CFD software is rather suitable for current LED lighting heat simulation. Chen and etc [7] established a compact-thermal model for LED package under different boundary conditions derived based on temperature and heat flow calculated by the detail finite volume model. The finite element method modeling for simulating the LED package with different heat slug, PCB, cooling condition and chip size are conducted in [8].The results are the thermal design rules and correlations for industry new LED lamp products development.Bai and etc[9] used CFD software for thermal simulation of a 3 core white LED downlight, analysised the material thermal resistance of thermal transverse channels such as substrate, solder, copper foil, aluminum substrate, etc;then a hybrid rapid thermal channel method which using copper to connect PN junction and external radiator is presented for heat dissipation optimization design of LED downlight.Ma[10] used finite element method to analysis and calculate temperature field of a $15 \mathrm{~W}$ LED downlight,further heat dissipation effect analysis of PCB thermal conductivity, thermal rubber heat conductivity and chips position(relative to the radiator fin type) were all taken in considered.

This paper will system analysis LED downlights dissipation of the relevant factors, such as power load, thermal resistence, material emissive, light source layout, etc. The research will be carried out mainly based on CFD software thermal simulation and experimental measurement. Section I is about heat dissipation modeling, and Section II is 
lab measurement and CFD heat simulation analysis, and then Section III is light source layout optimization.

\section{Heat Dissipation Modeling OF LED Downlight}

An 8 inch 25W power LED downlight is the main research object in this paper as shown in figure $1,3 \mathrm{D}$ model as shown in figure 2 .

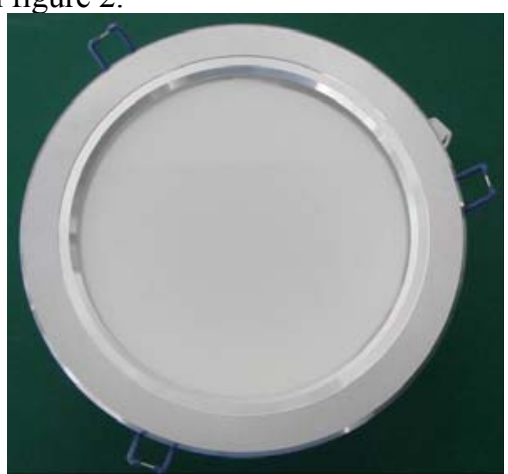

Figure 1. LED downlight

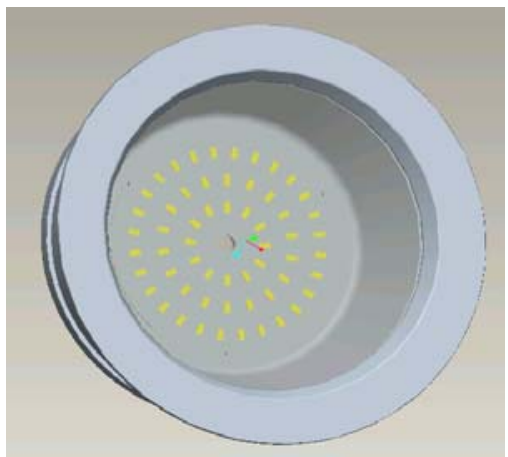

Figure 2. LED downlight 3D model

\section{A. Thermal Resistance}

Thermal resistance $\left(\boldsymbol{R}_{\mathrm{th}}\right)$ is defined as the heat resistance in the thermal channel, include two forms: material thermal resistance and contact thermal resistance.

1) Material thermal resistance is the ratio of thermal channel temperature difference $(\Delta T)$ and dissipated power $(\boldsymbol{P})$, see formula (1) [11]; it also can be calculated via the conductivity $(\boldsymbol{K})$ and thickness $(\boldsymbol{L})$ of material, as formula (2).

$$
\begin{array}{r}
R_{\mathrm{th}}=\frac{\Delta T}{P} \\
R_{\mathrm{th}}=\frac{L}{A * K}
\end{array}
$$

Where $\boldsymbol{A}$ is the effective cross-sectional areas of heat channel. Table 1 lists some commonly used material heat conductivity value $\boldsymbol{K}$.

TABLE I. MATERIAL HEAT CONDUCTIVITY VALUE K (W/M.K)

\begin{tabular}{ccccc}
\hline material & Al6063 & AL5052 & ADC12 & AL1060 \\
\hline $\begin{array}{c}\text { Thermal } \\
\text { conductivity }\end{array}$ & 201 & 138 & 163 & 300 \\
\hline
\end{tabular}

\begin{tabular}{ccccc}
\hline material & PBT & AL1060 & Glass & Epoxy \\
\hline $\begin{array}{c}\text { Thermal } \\
\text { conductivity }\end{array}$ & 0.274 & 0.189 & 0.7498 & 0.2 \\
\hline
\end{tabular}

2) Contact thermal resistance mainly occurs between the contact surfaces. Some heat channel material layer can be reflected in the modeling process because of its thickness is small, instead of setting an equivalent surface contact thermal resistance in the CFD simulation process. For example, light source LEDs were welded to aluminum substrate surface through reflow processing, then a contact thermal resistance between LED and aluminum substrate will be set to instead the soldering layer. The main material of reflow soldering layer is Tin $(96 \%)$, with the thickness of $0.1 \sim 0.15 \mathrm{~mm}$; thermal conductivity value is $60 \mathrm{~W} / \mathrm{m} . \mathrm{K}$.

As shown in figure.3, the aluminum substrate was constructed by a conductive layer, a heat insulating layer and a metal base layer. The conductive layer can be neglected for the large thermal conductivity and wee thickness; the main thermal resistance of aluminum substrate is decided by the heat insulating layer and the metal base layer, the former with little thickness but bad thermal conductivity, the latter with good heat conduction and large thickness. The simulation results will appear deviation if the aluminum substrate just settled to be one material.

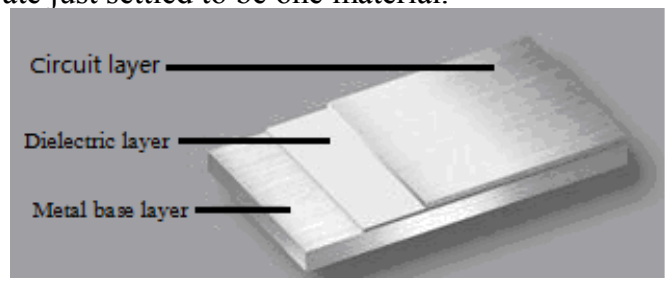

Figure 3. Aluminum substrate structure

According to above listed reason, an equivalent resistance $\left(\boldsymbol{R}_{\mathrm{e}}\right)$ is proposed to solve this problem. The insulating layer thermal resistance $\left(\boldsymbol{R}_{\mathrm{i}}\right)$ and the reflow soldering layer thermal resistance $\left(\boldsymbol{R}_{\text {Tin }}\right)$ can be converted into equivalent resistance through the formula (3):

$$
R_{e}=R_{\text {Tin }}+R_{i}
$$

Further, $\boldsymbol{R}_{\mathrm{e}}$ can be presented by equivalent thermal conductivity value $\left(\boldsymbol{r}_{\mathrm{e}}\right)$ and thickness $\left(\boldsymbol{h}_{\mathrm{i}}\right), \boldsymbol{r}_{\mathrm{e}}$ can be calculated from formula (4):

$$
r_{e}=\frac{\sum_{i=1}^{n} h_{i}}{\sum_{i=1}^{n} \frac{h_{i}}{r_{i}}}
$$

Where $\boldsymbol{r}_{\mathrm{i}}$ is the layer material conductivity value which can be found in Table.1, $\boldsymbol{h}_{\mathrm{i}}$ for each layer thickness. The aluminum substrate of LED downlight in this paper is come from Beggs Company with $1 \mathrm{~W} / \mathrm{m} . \mathrm{K}$ insulating layer conductivity and $0.076 \mathrm{~mm}$ thickness. Combined with the reflow solder references, $\boldsymbol{R}_{\mathrm{e}}$ can be calculated as $2.96 \mathrm{~W} / \mathrm{m} . \mathrm{K}$ conductivity and $0.076 \mathrm{~mm}$ thickness by formula (4).

Aluminum substrate is connected with the radiator through thermally conductive silicone or silicone gasket, the layer is set as $1.5 \mathrm{~W} / \mathrm{m} . \mathrm{K}$ and $0.5 \mathrm{~mm}$ for simulation. 


\section{B. Heat load}

Current lighting LED photoelectric conversion efficiency $\left(\boldsymbol{\eta}_{\text {LED }}\right)$ approximately $30 \%$, as a result nearly $70 \%$ of LED input power $\left(\boldsymbol{P}_{\mathrm{LED}}\right)$ converted into heat. Then the LED heat load $\left(\boldsymbol{Q}_{\mathrm{LED}}\right)$ is:

$$
Q_{L E D}=P_{L E D} *\left(1-\eta_{L E D}\right)
$$

Heat load calculation is an important link in the thermal simulation process. Heat load of LED lamps are mainly distributed in two regions: LED light source and power driver. LED downlight is with external power supply, so $25 \mathrm{~W}$ LED downlight only has $17.5 \mathrm{~W}$ heat load in the LED light source, and it can have two forms: volume heat source and surface heat source. Through experiments, we found that the CFD thermal simulation analysis results were not much difference, as shown in figure 4(a) and 4(b).
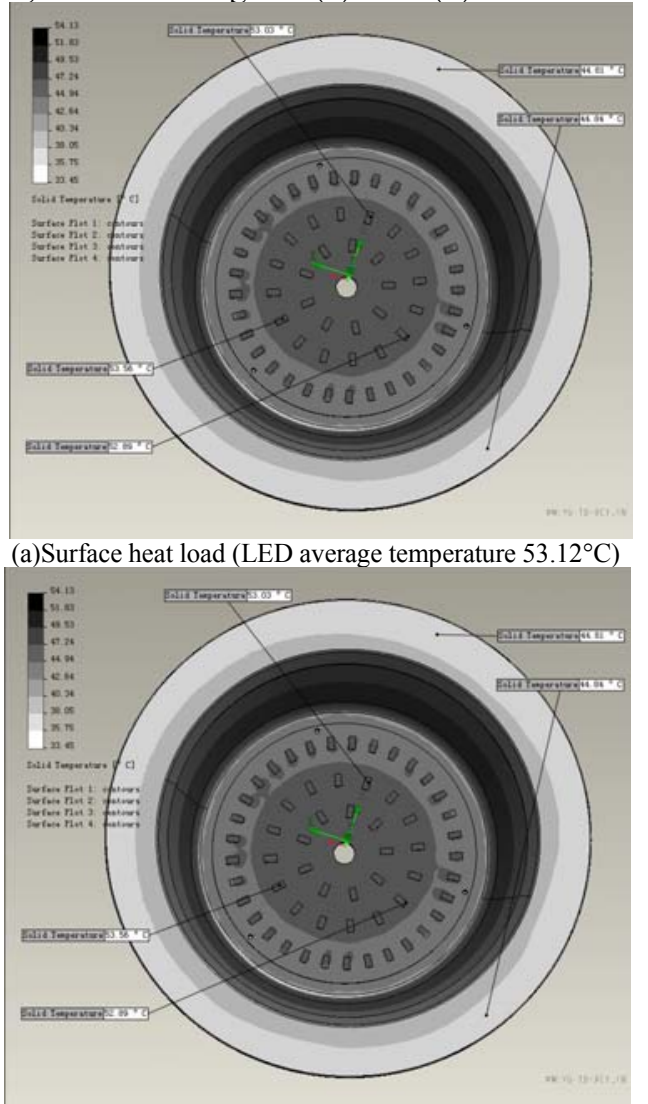

(b) Volume heat load (LED average temperature $53.51^{\circ} \mathrm{C}$ )

Figure 4. Different heat load form analysis

\section{Thermal Emissive}

Materials have different thermal emissive, and thermal emissive are not the same even if the same materials of different surface treatment processes [12]. Therefore, it must be clear about the material and surface treatment in the CFD thermal simulation process. Figure 5 shows the heat dissipation result of the same LED downlight with different radiator surface thermal emissive value(spun aluminum AL1060:0.65\&0.85).Comparison of several measuring positions' temperatures and maximum temperature of these two LED downlights, it can be found that, thermal emissive difference will eventually affect the entire LED lamp temperature field distribution.

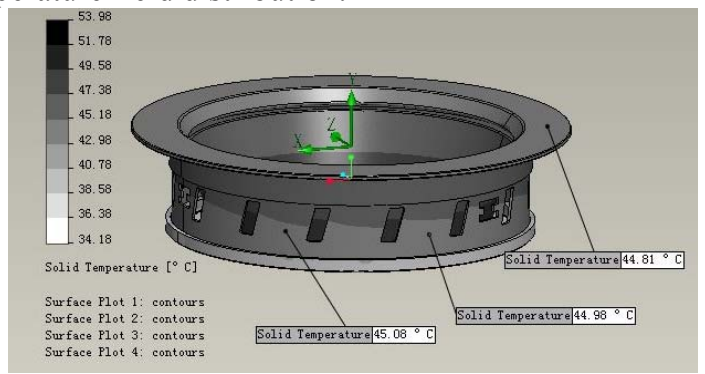

(a)AL1060 emissive of 0.65

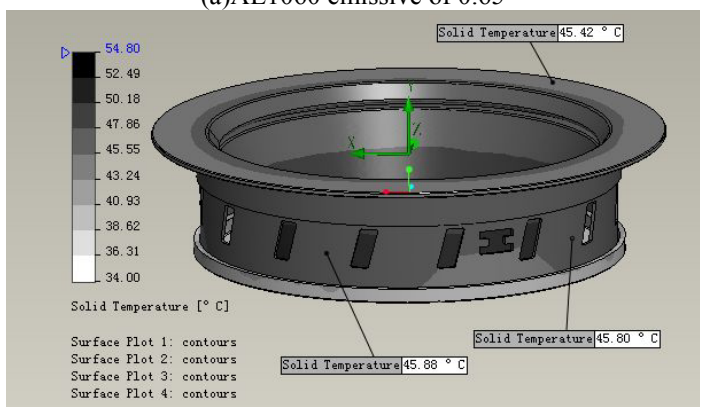

(b) AL1060 emissive of 0.85

Figure 5. Different thermal emissive analysis

\section{LAB MEASUREMENT AND CFD SiMULATION}

\section{A. Lab Measuring}

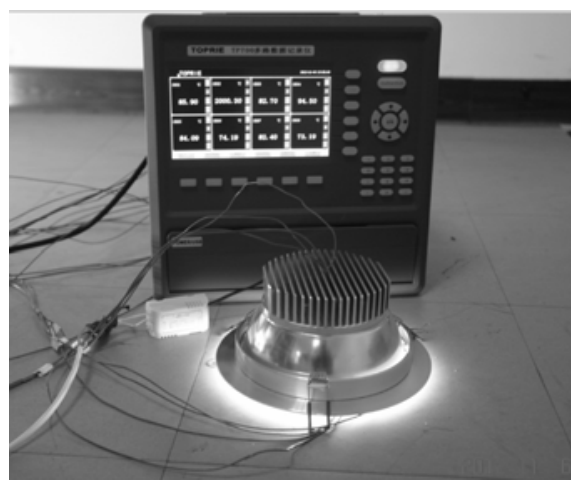

Figure 6. Temperature measurement platform

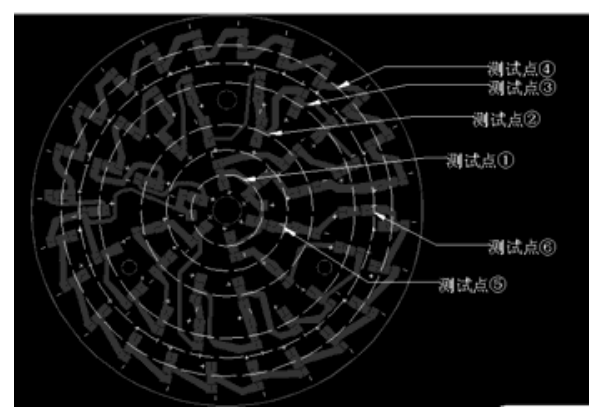


Figure 7. Temperature measurement positions on light source

Laboratory measuring experiment selected $25 \mathrm{~W}$ LED downlight, and the measurement device was 8 channels temperature measuring instrument TP700.The LED lighting laboratory temperature measurement platform was build as shown in figure 6 , measuring environment is no human moving and constant-temperature closed test room. Figure 7 shows the measuring positions, ambient temperature $26.7^{\circ} \mathrm{C}$.

\section{B. CFD Simulation}

25W 8 inch LED downlight used 60 pits medium power 5630 LED array light source, materials and heat conductivity value are shown in table. 2.

TABLE II. MATERIAL AND HEAT CONDUCTIVITY VALUE OF 25W LED DOWNLIGHT

\begin{tabular}{ccc}
\hline Part name & material & $\begin{array}{c}\text { thermal conductivity } \\
(\mathrm{W} / \mathrm{m} . \mathrm{K})\end{array}$ \\
\hline radiator & AL 1060 & 200 \\
alumina & AL 5052 & 138 \\
face ring & AL 1060 & 200 \\
lampshade & PC & 0.189 \\
LED & $\mathrm{Cu}$ & 390 \\
bonding material & silicone gasket & 1.5 \\
\hline
\end{tabular}

Setting the simulation ambient temperature $26.7^{\circ} \mathrm{C}$ too, CFD simulation results as shown in Figure 8.

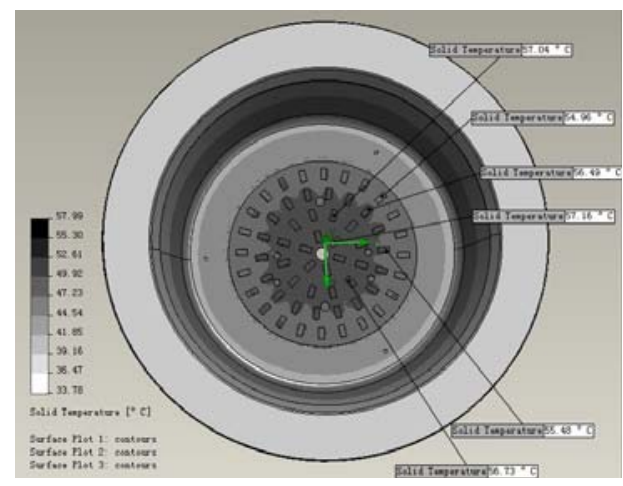

Figure 8. CFD simulation results

\section{Results analysis}

From table. 3 data shows that measured temperatures and simulated temperatures were very closer $(\leq 2 \%$ in error) of positions $2 \sim 6$. Therefore, the same parameters and boundary conditions will be used in follow-up optimization simulation experiment because of this simulation method is accurate and credible. It also can be found that just position 1 measured temperature was higher than simulated temperature about $5^{\circ} \mathrm{C}$, the main factors may be come from manufacturing, assemble process or measurement etc. So both the measurement and simulation are considered to be right, and position 1 high temperature shows that the temperature of most inner ring LEDs was significantly higher than the outer ring LEDs. Therefore, LEDs' working temperatures of the light source plate are difference of each other and this result will eventually lead to the inner ring LEDs have the shortest lifetime. Further more, it will impact the whole life of light source plate. Based on experimental and simulation results, layout optimization design of the light source is needed.

TABLE III. TEMPERATURE COMPARISON OF SIMULATION AND MEASUREMENT

\begin{tabular}{cccc}
\hline $\begin{array}{c}\text { Measuring } \\
\text { positions }\end{array}$ & $\begin{array}{c}\text { Lab measuring } \\
\text { temperature }\left({ }^{\circ} \mathrm{C}\right)\end{array}$ & $\begin{array}{c}\text { CFD simulation } \\
\text { temperature }\left({ }^{\circ} \mathrm{C}\right)\end{array}$ & $\begin{array}{c}\text { error } \\
(\%)\end{array}$ \\
\hline Position1 & 62.29 & 57.16 & -8.24 \\
Position2 & 57.90 & 57.04 & -1.48 \\
Position3 & 56.30 & 56.49 & 0.34 \\
Position4 & 56.00 & 54.96 & -1.86 \\
Position5 & 55.79 & 56.73 & 1.68 \\
Position6 & 55.20 & 55.48 & 0.51 \\
\hline
\end{tabular}

\section{LAYOUT OPTIMIZATION OF LIGHT SOURCE}

Heat dissipation, electrical, mechanical structure, optical and production technology and other factors must be taken into account all in light source layout optimization. For the size limitation of light aluminum substrate in $25 \mathrm{~W}$ LED downlight, the light source isn't having enough space for layout optimization if still use 4 rings LED layout. Therefore, 3 rings LED layout designed method is proposed. LED quantity and LED ring distance will be considered in the following thermal simulation, and after analysis process, an optimization light source layout will be presented.

\section{A. LED Quantity}

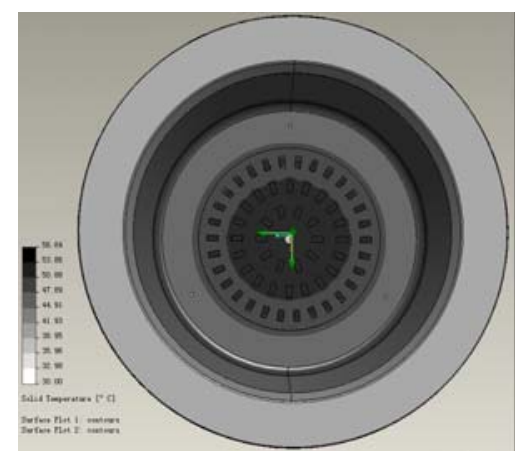

(a) 60 LEDs layout, maximum temperature $56.21^{\circ} \mathrm{C}$

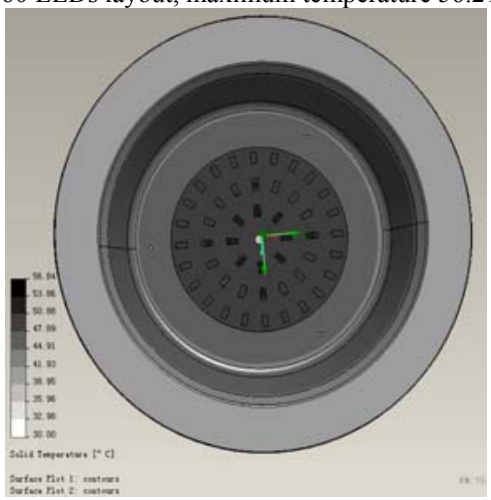

(b) 48 LEDs layout, maximum temperature $54.88^{\circ} \mathrm{C}$ 


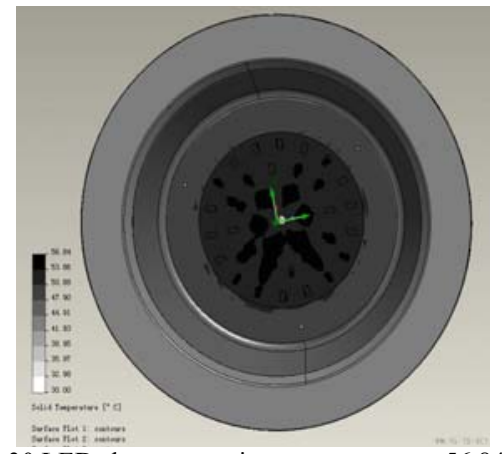

(c) 30 LEDs layout, maximum temperature $56.84^{\circ} \mathrm{C}$

Figure 9. CFD simulation results of different LED quantity

TABLE IV. TEMPERATURE COMPARISONS OF DIFFERENT LED QUANTITY

\begin{tabular}{cccc}
\hline LED quantity & 60 & 48 & 30 \\
\hline LED max temp $\left({ }^{\circ} \mathrm{C}\right)$ & 53.21 & 53.89 & 56.84 \\
LED avg temp $\left({ }^{\circ} \mathrm{C}\right)$ & 53.06 & 53.33 & 55.59 \\
LED min temp $\left({ }^{\circ} \mathrm{C}\right)$ & 52.36 & 52.95 & 53.63 \\
Radiator avg temp $\left({ }^{\circ} \mathrm{C}\right)$ & 47.16 & 46.96 & 45.44 \\
\hline
\end{tabular}

$25 \mathrm{~W}$ total power is kept unchanged, 3 rings LED include 60, 48 and 36 LEDs scheme are taken in considered. The mechanical structure, materials and all boundary conditions are same, the simulation results are shown in Figure 9, and data comparison can be seen in table 4 .

Comparisons from Figure 10 and Table 4, smaller LED power and large LED quantity should be better than others if the LED downlight power supply design is reasonable. The heat generated by the light source LEDs is uniform and dispersive because the heat coupling effect is decreased. Although LED quantity increased can make the heat dissipate well, but aluminum substrate wiring manufacturing and LEDs welding process will increase the difficulty; though few LED can make assemble and weld easily, but the single LED power is increased and this will result in local accumulation of heat. Comprehensive comparison, 48 LEDs light source arrangement is the right quantity for $25 \mathrm{~W}$ LED downlight.

\section{B. LED Ring Distance}

Looking into the light source plate size, three different LED distances simulation experiments are carried out. The ring distances will be $10 \mathrm{~mm}, 12 \mathrm{~mm}$ and $14 \mathrm{~mm}$.Contrast results seen in Table 5 .

TABLE V. TEMPERATURE COMPARISONS OF DIFFERENT LED RING DISTANCES

\begin{tabular}{cccc}
\hline LED distance $(\mathrm{mm})$ & 10 & 12 & 14 \\
\hline LED max temp $\left({ }^{\circ} \mathrm{C}\right)$ & 55.71 & 55.25 & 53.89 \\
LED avg temp $\left({ }^{\circ} \mathrm{C}\right)$ & 54.77 & 54.27 & 53.33 \\
LED min temp $\left({ }^{\circ} \mathrm{C}\right)$ & 53.95 & 53.52 & 52.95 \\
Radiator avg temp $\left({ }^{\circ} \mathrm{C}\right)$ & 46.19 & 46.20 & 46.96 \\
\hline
\end{tabular}

According to the simulation data comparison in Table 5, it can be found that $14 \mathrm{~mm}$ LED distance layout will have the best dissipation effect.

\section{Optimized Layout}

48 LED quantity and $14 \mathrm{~mm}$ LED ring distance was selected as light source optimization layout of $25 \mathrm{~W}$ LED downlight. Based on layout optimization, a new 25W LED downlight is produced and temperatures are measured in the same laboratory condition, and corresponding temperatures are compared with the results without optimization. Comparison results seen in Table 6, from the table we can see, the light source layout optimized LED lamps' working temperature is lower, especially LED maximum temperature drop about $10 \%$, obviously improved heat dissipation effect. This optimization can ensure the LED lifetime homogeneity of light source plate and improve the overall service life of LED downlights.

TABLE VI. TEMPERATURE COMPARISON OF LIGHT SOURCE LAYOUT BEFORE AND AFTER OPTIMIZED (AMBIENT TEMPERATURE $26.7^{\circ}$ )

\begin{tabular}{ccccc}
\hline project & $\begin{array}{c}\text { Before } \\
\text { optimized }\end{array}$ & $\begin{array}{c}\text { after } \\
\text { optimized }\end{array}$ & $\begin{array}{c}\text { Temp } \\
\text { difference }\end{array}$ & $\begin{array}{c}\text { Percent } \\
(\%)\end{array}$ \\
\hline LED max temp $\left({ }^{\circ} \mathrm{C}\right)$ & 63.50 & 57.21 & -6.29 & -9.9 \\
LED avg temp $\left({ }^{\circ} \mathrm{C}\right)$ & 57.61 & 55.41 & -2.20 & -3.82 \\
LED min temp $\left({ }^{\circ} \mathrm{C}\right)$ & 54.70 & 53.92 & -0.78 & -1.43 \\
Radiator temp $\left({ }^{\circ} \mathrm{C}\right)$ & 46.98 & 47.56 & 0.58 & 1.22 \\
\hline
\end{tabular}

\section{CONCLUSION}

In this paper, LED downlight three-dimensional mathematical model was established for heat dissipation simulation. Considering the impact of lamp radiating material, thermal resistance, thermal emissive, heat load and other relevant factors, and then using CFD thermal simulation software combined with laboratory measurement method to analysis the lamp heat dissipation. On this basis, focusing on dissipation effects of both LED quantity and LED rings distances of light source plate. Research showed that the source layout should be designed on relationship of LED quantity and LED rings distances, in order to reduce the thermal coupling between the light source LEDs or heat localized accumulation. Only in this way, LED lamp lifetime and reliability can be ensured. Through laboratory measurements, LED downlight with light source layout optimized whose working temperatures are more ideal, and this can effectively improve the lifetime of the whole LED lamp. The paper's research has important guiding significance in practical of LED downlight design future.

\section{ACKNOWLEDGMENT}

This work was supported by a grant from the National High Technology Research and Development Program of China (863 Program) (N0.2011AA03A109); National Key Technology Support Project (N0.2011BAE01B10).

\section{REFERENCES}

[1] Arik M, Beckerb C, Weaverb S, et al. Thermal management of LEDs : Package to system[J].Proc SPIE,vol.5(187),pp.64-75,2004

[2] X.W. Mao,Y.W. Zhang,J.J. Zhou,et al.A new generation of green LED light source and its application[M].Posts \& Telecom Press,Beijing,2008. 
[3] Z.R. Lin,S.F. Wang,J.P. Huo,et al.Heat transfer characteristics and LED heat sink application of aluminum plate oscillating heat pipes[J].Applied Thermal Engineering,(31),pp.2221-2229,2011

[4] J.H. Xiang,B.Y. Ye,Y. Tang,et al.Forming technology of boiling structure on evaporation surface of phase-change heat sink for highpower light emitting diode [J]. Journal of Central South University of Technology,vol.17(3),pp.544-548,2010

[5] J.H. Xiang,C.L. Zhang,F. Jiang,et al.Fabrication and testing of phase change heat sink for high power LED[J].Transactions of Nonferrous Metals Society of Chang, (21),pp.2066-2071,2011

[6] M.T. Lin,S.P. Ying,M.Y. Lin,et al.High power LED package with vertical structure[J].Microelectronics Reliability,(52),pp.878-883, 2012

[7] H. Chen, Y. Lu, Y. Gao, et al. The performance of compact thermal models for LED package[J].Thermochim. Acta,(488),pp.33-38,2009
[8] C.J. Weng.Advanced thermal enhancement and management of LED packages[J].Int. Commun. Heat Mass Transf, (36),pp. 245-248,2009

[9] K. Bai,L.G. Wu,Q.H. Nie,et al.High-release package design and analysis of high-power white LED down light[J].Optical Technique,vol.38(3),pp.300-304,2012

[10] X.J. Ma,L.G. Wu,S.X. Dai,et al.Thermal analysis of high-power LED downlight[J].China Illuminating Engineering Journal,vol.22(16),pp. 18-21,2011

[11] C.J. Weng. Advanced thermal enhancement and management of LED packages[J].International Communications in Heat and Mass Transfer, vol.36(3),pp.245-248,2009

[12] H.H. Wu,K.K. Lin,S.T. Lin.A study on the heat dissipation of high power multi-chip COB LEDs[J].Microelectronics Journal,(43),pp. $280-287,2012$ 